\title{
Residential Water Demand under Alternative Rate Structures: a simulation approach
}

\author{
David E. Rosenberg \\ Department of Civil and Environmental Engineering and \\ Utah Water Research Laboratory \\ Utah State University \\ Logan, UT, USA. \\ Email: david.rosenberg@usu.edu
}

Submitted to ASCE-Journal of Water Resources Planning and Management

WRENG-121

Submitted: December 10, 2008

Resubmitted: May 19, 2009

Resubmitted: July 20, 2009

Accepted: August 3, 2009 


\title{
Residential Water Demand under Alternative Rate Structures: a simulation approach
}

\author{
David E. Rosenberg \\ Department of Civil and Environmental Engineering and Utah Water Research Laboratory \\ Utah State University \\ Logan, UT, USA. \\ Email: david.rosenberg@usu.edu
}

\begin{abstract}
Econometricians have long studied the effect of price on residential water demand and the impact on water use of the rate (tariff) structure in which price signals are embedded. This paper applies an existing deductive model of residential water use for the intermittent supply system in Amman, Jordan and simulates demand responses across a cross-section of households over many uniform, increasing block, and linear price (quadratic charge) rate structures at historically low and significantly higher prices. Results show inelastic piped water demand responses for all rate structures at historically low prices similar to findings from a prior econometric study for Amman. However, piped water demand turns more elastic when prices rise above $\$ 0.50 / \mathrm{m}^{3}$ with uniform rates showing the most elastic response. But results also highlight several complications to determine and interpret price elasticity of demand under different rate structures. They also illustrate tradeoffs among rate structures and rate structure components for key rate setting objectives such as to encourage water conservation, recover costs, promote efficiency and more equitably allocate costs among users.
\end{abstract}

Keywords: household, water, demand, price schedule, price elasticity, simulation-optimization

\section{Introduction}

Water utility managers and economists have long been interested in the effect of price on household water use as a tool to manage demand (Howe and Linaweaver 1967; Young 2005). Econometric studies typically quantify price effects as elasticities that express the percentage change in water use associated with a one percent increase in price. Price-elasticity of water demand is generally observed as negative and less than 1 in absolute value (inelastic). However, significant differences exist and relate to the econometric regression technique, price specification, and rate structure in the study area (Dalhuisen et al. 2003; Espey et al. 1997). Of particular interest is how to incorporate flat charges, variable prices, and nonlinear rate structures that present different prices for different levels of water use.

When setting prices, utilities often grapple with conflicting objectives such as to promote efficiency, encourage conservation, maintain revenue neutrality (generate revenues only to recover costs), achieve equity, make rates easy to implement and transparent to users, plus satisfy other political aims 
(Chesnutt and Beecher 1998; Hanemann 1998). Balancing these many considerations is difficult and there is no single method or technique utilities use to identify and set prices.

Even resolving influences of the rate structure on water use or conservation potential through econometric (regression) analysis has proved tricky. First, price varies with water use in nonlinear price structures such as increasing or declining block rates (IBR and DBR) or linear price (resulting in quadratic charge) schemes. Thus, price is endogenous (Olmstead et al. 2007). Second, using marginal or average prices in regressions can change interpretations of price responses (Young 2005). Third, flat charges for connection and metering fees plus IBR or DBR price blocks can confound the calculation of price, particularly average price. Fourth, households often know little about prices and the rate structures in which prices are embedded; this ignorance affects price responses (Agthe et al. 1988; Carter and Milon 2005; Gaudin 2006). Further, ex-post billing, excluding price information from bills, or bundling water with other utility services make price information less transparent to customers (Gaudin 2006). Fifth, low water prices in the U.S. (Brookshire et al. 2002) and Jordan (Alqam et al. 2008) have limited the range of prices over which demand responses have been observed.

Sixth and finally, results are mixed from the few individual studies (Table 1) and meta analyses (Table 2) that have tried to differentiate the demand effects of multiple rate structures (Dalhuisen et al. 2003; Espey et al. 1997; Kenney et al. 2008; Nieswiadomy and Cobb 1993; Nieswiadomy and Molina 1989; Olmstead et al. 2007; Stevens et al. 1992). Curiously, the individual studies attempt to quantify rate structure effects as price elasticities of demand, imply that rate structure changes shift demand, and/or embed rate structure differences into average or marginal price variables. Yet, a monopolist water utility that changes prices and the rate structure in which prices are embedded may only influence where along the supply curve users choose to situate their water use. Further, different elasticity responses may relate to different data analyzed (aggregate, panel, etc.), omitted variables that correlate with price, a sample selection bias potentially present in panel studies (Nieswiadomy and Cobb 1993), or how the actual rate structure in the study area mathematically interacts with the modeled price variable

61 (average, marginal, Shin, etc.).

To identify the effects of different rate structures and price schedules with a single cross-sectional sample, this paper applies an existing deductive model of individual household water use for Amman, Jordan (Rosenberg et al. 2007). We simulate several rate structures for public, piped water over a variety of historical and higher price schedules. The Amman system is intermittently operated and typically supplies customers for only 12 to 72 hours per week. Thus, customers also adopt a range of alternative supply, coping behaviors, and even discontinue piped water service when its cost, availability, or reliability are lacking. To represent these conditions, the deductive model identifies the expected, cost-minimizing mix of piped water and alternative supply, conservation, local storage, and water quality improvement actions an individual household can adopt to meet its water needs. We use Monte-Carlo simulations to represent household heterogeneity. We calculate an average and marginal price for each rate structure and price schedule, observe changes in these prices and household water use over different price schedules, and from these intermediary results calculate a price elasticity of demand for each rate structure. The deductive model requires significant time to construct, detailed 
opportunities programmed in, makes assumptions on the initial water required for household activities, uses an imperfect decision criteria, and is partially validated against econometric results of observed water use behaviors. However, deductive modeling and rate structure simulation allow cross-sectional analysis in a single community for numerous pricing mechanisms at existent and higher prices. Further, results can include tradeoffs between rate structures and rate structure components for important rate setting objectives such as to promote efficiency, encourage water conservation, recover costs, and more equitably allocate costs among users. This information is timely as the Amman water utility seeks new price mechanisms to better recover utility costs from customers (Alqam et al. 2008).

The paper proceeds as follows. The next section reviews the deductive model formulation, inputs, and outputs. Subsequent sections present and discuss the rate structures and price schedules simulated, model results, and conclusions.

\section{Deductive Model of Water Use}

The deductive model identifies an individual household's expected, cost-minimizing mix of public, piped water supply, alternative sources, conservation actions, local storage enhancements, and water quality improvements having variable costs, availabilities, reliabilities, and qualities to meet initial estimates of the household's water use requirements across a probability distribution of piped water availability. The action mix includes many water-related actions users take in intermittent systems and can include alternative sources and coping behaviors in lieu of public, piped water. See Rosenberg et al. (2007) for full details. This section reviews the model formulation, inputs, outputs, calibration, and verification.

Household water management actions include 39 potential long-term infrastructure investments (connecting to the piped water network, installing roof or ground-level storage tanks, water efficient appliances, xeriscaping, drip irrigation systems, etc.) and short-term coping actions (such as purchasing water from private vendors, borrowing from neighbors, or modifying behaviors to, for example, take shorter or less frequent showers or stress-irrigate landscaping). This action set is much more expansive than prior deductive models of water use (Garcia-Alcubilla and Lund 2006; Howe et al. 1971).

The deductive model draws on different empirical data and studies for Amman, Jordan to characterize potential household actions, behaviors, and conditions (Rosenberg et al. 2008; Rosenberg et al. 2007). In all, we use available empirical data and engineering judgment to develop probability distributions for some 126 parameters that influence action costs, life spans, availability and reliability, effective water volume added or conserved, and initial estimates of a household's water use requirements. Probability distributions include uniform, normal, exponential decay, fitted gamma, and histograms and depend on prior available empirical data (Rosenberg et al. 2007). Some parameters (like household size, rainfall, and landscaped area) have direct analogues to econometric model variables. We disaggregate other typical econometric variables (like price, building age, education level, and income that are proxies for phenomena of interest like the rate structure, stock of water use appliances, or conservation mindedness of users) into separate parameters such as prices and block spacing, flow rates for each water appliance, lengths and frequencies of appliance uses, etc. And still other parameters like

113 availabilities (water volumes) and reliabilities (probabilities) of piped water and alternative sources 
114 (typically absent from econometric studies) represent intermittent system characteristics that may force 115 households to adopt alternative supplies or actions when piped water supply is insufficient. The model 116 for Amman assumes households face three discrete water availability-reliability events: (i) summer 117 weeks with shortage, and (ii) summer and (iii) winter weeks with full availability. In all, probability 118 distributions for the 126 parameters comprise household demographic, geographic, technological, 119 behavioral, cost, and water availability factors that influence a household's water use.

120 We used Monte-Carlo simulations to sample from the 126 probability distributions. Second, we

121

122

123

124

125

126

127

128

129

130

131

132

133

134

135

136

137

138

139

140

141

142

143

144

145

146

147

148

149

150

151

152

combined sampled values using explicit formulas to estimate optimization model inputs for a large number of simulated customers. Sampling and combining allows detailed disaggregation, correlation, and contingent sampling among the 126 parameters to create a heterogeneous cross-sectional sample of households. Third, we ran the optimization model for each simulated customer to identify the expected (probability-weighted) cost-minimizing strategy (piped water supply, alternative sources, conservation actions, etc., associated water use and charges for those actions) the household would choose to meet its water use requirements across all availability events. And fourth, we recorded averages and distributions of optimization results.

Rosenberg et al. (2007) discuss model calibration to the cumulative distribution of piped water billed to Amman residential customers in 2005. They adjusted only 1 of 126 empirical parameters, occupancy, and used the historical mixed IBR/linear price (quadratic charge) rate structure for combined piped water and sewerage charges in place between 2001 and 2005. This rate structure had four blocks with flat, uniform, and linear prices for use below, respectively, 20,40, and $130 \mathrm{~m}^{3} /$ customer/quarter. Use above $130 \mathrm{~m}^{3} /$ customer/quarter reverted to a uniform price. Prices ranged from $\$ 0.26 / \mathrm{m}^{3}$ in block 2 , $\$ 0.81$ to $\$ 3.27 / \mathrm{m}^{3}$ in block 3 , and $\$ 1.75 / \mathrm{m}^{3}$ in block 4 . The modeled piped water use averaged 152 $\mathrm{m}^{3}$ /customer/year with $45 \%$ of customers using less than $90 \mathrm{~m}^{3} /$ customer/year. A Kolmogorov-Smirnov (K-S) test showed the calibration fit significant at the $98 \%$ level.

Rosenberg et. al (2007) further verified the deductive model against (i) an empirical distribution of willingness-to-pay to avoid network shortages reported by a contingent valuation survey of 1,000 Amman households (Theodory 2000), and (ii) demand responses to the Amman price schedules instituted in 1997, 2001 (base calibration), and 2006. The three historical price schedules had the same block spacing and pricing mechanisms. The 2001 schedule increased all uniform sewerage prices from 1997 by $12 \%$ while the 2006 schedule further increased flat charges in each block by amounts ranging from \$US 2.33 to 5.15/customer/quarter. We simulated each price schedule, observed the average piped water use, and calculated an average price (total utility revenues from all simulated customers divided by the total piped water use). We estimated a slope from the changes in piped water use and calculated average prices across the three price schedules, then calculated a point price elasticity of demand from the slope at the base calibration piped water use and average price (Rosenberg et al. 2007 , Table 1). This calculated elasticity was close to the price elasticity of demand reported by an econometric study of Amman households over the same time period (Salman et al. 2008).

The remainder of this paper simulates piped water use and calculates ssociated price elasticities of demand for several alternative uniform, IBR, and linear price (quadratic charge) rate structures at 
historical and higher prices. Analysis focuses on demand responses, economic efficiency, cost allocation among and recovery from users, and tradeoffs between rate structure components.

\section{Rate Structures Simulated}

Figure 1 shows how marginal prices and total charges can vary with consumption for several rate structures. From the figure, note:

1. Raising or lowering the price schedule for one rate structure relative to others can adjust price ordering and test, through simulation, effects to increase prices.

2. A uniform rate structure with no flat fee plots at the same marginal price as a uniform rate with a flat fee (assuming the uniform prices are the same).

3. When use by all users facing an IBR falls in the first block, the IBR is effectively a uniform structure. Raising prices in higher use blocks will not impact water use. To study this effect, we introduce simulations that hold IBR prices constant but shrink block widths (spacing).

Table 3 presents the 53 price schedules simulated for 4 different rate structures. IBR price schedules maintained historical block spacing but varied prices in each block from $1 / 2$ to 8 times their historical values. IBR with shrinking block width price schedules held prices in each block constant at 1.5 times their historical values but varied block widths for the first 3 blocks from 1.5 to 0.25 times their historical values. Linear price (quadratic total charge) schedules increased the quadratic price term from $\$ 0.007$ to $\$ 0.037 / \mathrm{m}^{6}$. The quadratic price term of $\$ 0.011 / \mathrm{m}^{6}$ approximated historical prices in blocks 1 to 3 up to consumption of $116 \mathrm{~m}^{3} /$ customer/quarter. Uniform rates tested combinations of many prices and flat charges. One series varied a single price from $1 / 3$ to 6 times the historically average price of $\$ 0.42 / \mathrm{m}^{3}$ with no flat charges. Other series varied flat charges from $-\$ 45$ to $+\$ 45 /$ customer/quarter at three separate prices, $\$ 0.71, \$ 1.06$, and $\$ 1.41 / \mathrm{m}^{3}$. Here, negative flat charges represent a utility incentive and return money to customers who use less water than a proscribed target. Alternatively, high flat charges may encourage customers to discontinue piped service and seek alternative sources. To date, few utilities use negative flat fees and utilities prefer to keep rather than drive away customers. Deductive modeling and rate structure simulation can serve as a useful tool to evaluate these effects.

\section{Results}

Figure 2 shows piped water demand responses for the rate structure and price schedule simulations. The average price (top) is calculated as total utility revenues from all Monte Carlo simulations divided by total piped water use. The marginal price (bottom) is the price paid at the average piped water use. Table 4 shows ranges of point price elasticities calculated using the two prices. Observe:

1. At low prices (at or below historical prices), the model predicts inelastic demand responses for all rate structures. Average and marginal prices both give similar elasticity estimates. 
2. Demand responses appear more price elastic as prices increase above $\$$ US $0.5 / \mathrm{m}^{3}$. Also, there is a wider range in elasticity estimates.

3. At high prices for the linear rate structure, marginal prices are higher than average prices for the same piped water use; price response is more elastic when calculated from average prices.

4. Conversely, marginal prices are the same for IBR with shrinking block width and uniform price schedules that vary flat charges. In these cases the calculated slope is zero, elasticity infinite, and marginal price is not a meaningful indicator. Deductive modeled households respond to expected total cost (which includes flat charges), some discontinue piped water use, and switch to alternative sources. Piped water use changes but the marginal price variable does not capture the changing flat charge component of the piped water rate structure.

5. The uniform rate structure and price schedules with (i) no flat charges and (ii) price of $\$ 1.41 / \mathrm{m}^{3}$ with changing flat charges show the most elastic price responses.

At sufficiently high prices, each rate structure can significantly reduce piped water use from the use observed in 2005. However, rate structure motivated water conservation imposes significant costs on households (Figure 3, bottom left). For example, at historical piped water rates, the average household pays about $\$ 240 /$ year in total costs for their piped water, alternative sources, and coping behaviors. If the utility adopts an IBR with shrinking block width rate structure to reduce piped water use to 120 $\mathrm{m}^{3}$ /customer/year, the average household's total costs would increase $42 \%$ to $\$ 338 /$ year. Here, total cost represents economic efficiency because it measures the total losses (or gains) when all households respond to different rate structures for piped water. Although the IBR, IBR with shrinking block width, and linear price rate structures are economically efficient choices to encourage water conservation, they still impose significant additional costs on users compared to historical costs.

The uniform price schedules with low prices and no flat charges are economically efficient and impose low total costs for users, but recover only a small fraction of utility costs (Figure 3, middle). Here, we calculate cost recovery by dividing utility revenues by the Amman utility's variable and fixed costs of approximately $\$ 0.94 / \mathrm{m}^{3}$ and $\$ 42.5 /$ customer/year (Alqam et al. 2008). Note that historical price schedules (which significantly subsidize use in blocks 1 and 2) recover less than 65\% of utility costs. Certain revenue neutral IBR, IBR with shrinking block width, and linear price (quadratic charge) price schedules simultaneously reduce water use to approximately $120 \mathrm{~m}^{3} /$ customer/year. However, other revenue neutral IBR and uniform rate structures with and without flat charges impose lower total costs on users but maintain water use near the historical average of approximately $150 \mathrm{~m}^{3} /$ customer/year.

Plotting the user distribution against the cumulative share of total piped water charges users pay shows cost distribution among users for the revenue neutral piped water price schedules (Figure 4). These Lorenz curves show more equitable cost allocation compared to the 2005 historical schedule. For example, the uniform and IBR price schedules collect nearly $18 \%$ of total utility revenues from the first $45 \%$ of users with the lowest water use. In contrast, the 2005 price schedule collected less than $5 \%$ of total revenues from the same fraction of users and more than $60 \%$ of total revenues from the largest $10 \%$ of users. In Figure 4, larger deviations from the 1:1 line of perfect equity (that represents a flat 
charge structure where all users pay the same amount regardless of use) highlight larger cost allocation inequalities. We quantify inequalities by the Gini coefficient which measures the area between the 1:1 line of perfect equity and the Lorenz curve. Thus, the uniform price schedule with a uniform charge of $\$ 0.71 / \mathrm{m}^{3}$ and flat charge of $\$ 23 /$ quarter appears most equitable. All the revenue neutral piped water price schedules more equitably allocate costs among users than the 2005 rate schedule, however, they impose significant additional total costs on users compared to the historical rate structure.

The top left and right panels of Figure 3 show the tradeoffs between cost allocation equity, water use, and user's total costs for each simulated rate structure. Here two results are notable. First, the IBR and linear price structures simultaneously and significantly improve cost allocation among users and reduce water use compared to the $\mathbf{2 0 0 5}$ historical rate structure. However, these two rate structures also significantly increase user's total costs and are not the most economically efficient options to promote cost equity. Second, uniform price schedules with (i) low prices and no flat charges, and (ii) a price of $\$ 0.71 / \mathrm{m}^{3}$ and flat charges improve cost allocation among users and maintain user's total costs near historical levels. These price schedules more efficiently promote more equitable cost allocation among users, but maintain water use at historical levels and are not conservation oriented.

Figure 5 further highlights tradeoffs among rate setting objectives for the uniform rate structure's flat charge ( $x$ axis) and price (traces) components. Flat charges at or just above $\$ 0 /$ customer/quarter most equitably allocate costs among users and have similar Gini coefficient values for all prices. As flat charges fall below zero, water use is largely insensitive to the uniform price component. However, as flat charges increase, water use decreases faster at higher uniform prices. Several combinations of uniform prices and flat charges between $-\$ 10$ and $\$ 10 /$ customer/quarter appear to simultaneously maintain user's total costs near historical levels and promote full cost recovery. For example, price schedules with prices of $\$ 1.06$ and $\$ 1.41 / \mathrm{m}^{3}$ and no flat charges slightly increase users' total costs, attain full cost recovery, maintain historical piped water use levels, and improve cost allocation among users. Flat charges above $\$ 25 /$ customer/quarter appear to make the Amman utility into a profit making enterprise and are likely not desirable. Deductive model results highlight demand responses for different rate structures and show tradeoffs among important rate-setting objectives such as to promote efficiency, encourage conservation, recover costs, and more equitably allocate costs among users.

\section{Discussion, Limitations, and Further Research}

The price elasticity, water use, cost recovery, cost allocation, and total cost (economic efficiency) results presented above highlight several significant findings which we now identify and discuss further.

First, deductive modeling of household water management decisions and simulation under the existing mixed IBR/linear price (quadratic charge) structure in Amman, Jordan at low historical prices reproduces the highly inelastic price elasticity of demand found by an econometric study over the same time period (Salman et al. 2008). Second, demand responses for the other rate structures simulated at low historical-like prices is also very price-inelastic. 
Third, demand response becomes much more price-elastic at prices above $\$ 0.5 / \mathrm{m}^{3}$. However, the magnitude of the demand response for non-linear rate structures depends on both the rate structure simulated and price variable used. These mixed results help explain contradictory findings by prior econometric studies (Kenney et al. 2008; Nieswiadomy and Cobb 1993; Nieswiadomy and Molina 1989; Olmstead et al. 2007; Stevens et al. 1992).

Fourth, rate structures and price schedules pose important tradeoffs among rate setting objectives such as to promote efficiency, encourage conservation, recover costs, and equitably allocate costs among users. To recover $100 \%$ of costs and achieve revenue neutrality, the Amman utility will likely need to increase above $\$ 1.0 / \mathrm{m}^{3}$ the average price paid by the typical customer. These price increases are similar to recent results reported by a cost recovery study for Amman (Alqam et al. 2008). However, Alqam et al. (2008) only examined uniform price schedules and did not consider effects on efficiency, water use, or cost allocation among users. In this regard, the efficient, revenue neutral rate structures that keep users' total costs low are uniform price schedules with prices between $\$ 0.71$ and $\$ 1.41 / \mathrm{m}^{3}$ and flat charges between $\$-11$ and $\$ 23 /$ customer/quarter (see Figure 4). These price schedules also maintain water use, more equitably allocate costs, and will, on average, only increase user's total cost by $\$ 80 /$ customer/year compared to the historical rate structure. The existing mixed IBR/linear rate structure subsidizes most users in the first two blocks, recovers less than $65 \%$ of costs, and motivates significant increases in prices and user's total costs to achieve revenue neutrality.

Deductive model results also show that IBR, IBR with shrinking block width, and linear price schedules appear conservation oriented because they can significantly reduce water use, recover costs, and more equitably allocate costs among users. However, these rate structures, on average, increase user's total costs more than $\$ 120 /$ customer/year over the existing rate structure. And despite estimated reductions of approximately $30 \mathrm{~m}^{3} /$ customer/year, the $\$ 4 / \mathrm{m}^{3}$ user cost for conserved water with these rate structures is much more expensive than the $\$ 1-2 / \mathrm{m}^{3}$ cost of the Amman utility's other supply options, Zara Ma'een, the Disi aquifer, and the Red-Dead canal (Alqam et al. 2008). The conservation oriented rate structures only become attractive if the comparison point is a revenue-neutral uniform structure discussed above rather than the existing mixed IBR/linear rate structure.

Rosenberg et al. (2007) present limitations of deductive modeling which we summarize here. First, the model assumes simulated households minimize costs to meet initial estimates of water use. These initial estimates set upper bounds for optimal uses; simulated customers can choose from an exhaustive set of supply or conservation actions to set use at or below the initial estimate, but they have no incentive to increase use beyond initial estimates such as to expand their garden area or take longer or more frequent showers should water prices decrease or water become more available. Put another way, the model is built and calibrated to current and prior water use behaviors observed when only a small volume of cheap water was available to users. Second, households minimize their expected water management costs rather than maximize utility or minimize cost deviations. This decision criteria assumes households are risk neutral not risk adverse or risk taking. Yet, deductive model calibration and verification suggest Amman households behave as if they minimize their expected water-related costs. And third, households minimize their expected costs with perfect information about the piped water rate structure and alternative water management actions. Carter and Milon (2005) and Gaudin (2006) 
report that households often have limited knowledge of the rate structure and price schedule. However, recent work in Jordan finds that households understand the historical rate structure and the steep additional costs associated with consuming in higher blocks (Rosenberg et al. 2008).

Based on the above results and limitations, further research should empirically verify deductive model results for all rate structures at prices both significantly above and below historical prices. Verification will require either (i) a fortuitous cross-sectional time-series dataset, or (ii) observing changes in water use associated with a community intervention study where random subsamples of the community faced different rate structures and price schedules. Adding and crossing price interventions with informational interventions (such as water audits or bill inserts that indicate the price paid, ways to save water or money, use history, and/or use compared to community norms) could simultaneously disentangle the combined effects of price and price information. Analyzing results using both econometric and deductive models can help improve both types of models.

\section{Conclusions}

Deductive modeling identifies the mix of actions and water uses a perfectly informed household adopts to reduce its expected water management costs given a probability distribution of piped water availability. Monte Carlo simulations show distributions of customer responses and cumulative citywide effects, including piped water use, total user costs, utility cost recovery, and cost allocation among users. We calculate price elasticity by simulating household responses to several price schedules and observing resulting changes in average piped water use and prices across the price schedules.

Model calibration reproduces both the average and distribution of billed piped water use in Amman, Jordan in 2005. The model was further verified against (i) a distribution of willingness-to-pay to avoid network shortage reported by a contingent valuation study, and (ii) an econometric price elasticity estimate for Amman between 1997 and 2006. Subsequently simulating IBR, IBR with shrinking block widths, linear price, and uniform rate structures at prices ranging from 0.5 to 8 times historical values allows cross-sectional analysis in a single community and suggests:

1. The Amman utility will need to increase prices to or above $\$ 1.0 / \mathrm{m}^{3}$ to recover costs. Uniform structures with prices between $\$ 0.71$ and $\$ 1.41 / \mathrm{m}^{3}$ and flat charges between $\$-11$ and $\$ 23 /$ customer/quarter will likely pose the least total cost burden to users.

2. At higher prices, uniform or IBR structures show the most elastic price responses.

3. However, at higher prices, price responses vary and depend on the average or marginal price variable used to calculate elasticity.

4. Conservation-oriented IBR, IBR with shrinking block width, and linear price rate structures seem best able to simultaneously reduce water use, recover costs, and more equitably allocate costs among users. However, these rate structures significantly increase users' total costs with the likely benefits from conservation less than the added costs the rate structures impose on users. 
5. The conservation-oriented rate structures may be desirable if compared to a revenue-neutral uniform rate structure rather than the existing and historical mixed IBR/linear rate structure.

6. The Amman utility can adjust flat and uniform price components of a uniform structure to simultaneously promote efficiency, recover costs, and more equitably allocate costs among users.

Overall, deductive modeling and rate structure simulation shows how to integrate various rate structure, pricing, conservation, water availability, and other household behavioral factors into a common approach to model and understand household water use in intermittent supply systems. Further, modeling indentifies tradeoffs among rate structures and price schedule components to achieve key rate setting objectives such as to promote efficiency, reduce water use, recover costs, and more equitably allocate costs among users.

\section{Acknowledgements}

Anita Milman, Arthur Caplan, and several reviewers made helpful comments to improve earlier drafts.

\section{References}

Agthe, D. E., Billings, R. B., and Dworkin, J. M. (1988). "Effects of rate structure knowledge on household water-use." Water Resources Bulletin, 24(3), 627-630.

Alqam, I., Cumiskey, P., Gonzales, L. M., Hidmi, L., Ringskog, K., Yepes, G., and Valdez, J. (2008). "Amman water management commercialization part 1: pricing of water and wastewater services in Amman and subsidy options-conceptual framework and recommendations." Contract No. AFP-I00-03-00035-00, Task Order No. 539, U.S. Agency for International Development, Amman, Jordan.

Brookshire, D. S., Burness, H. S., Chermak, J. M., and Krause, K. (2002). "Western Urban Water Demand." Natural Resources Journal, 42(4), 873-898.

Carter, D. W., and Milon, J. W. (2005). "Price knowledge in household demand for utility services." Land Economics, 81(2), 265-283.

Chesnutt, T. W., and Beecher, J. A. (1998). "Conservation rates in the real world." Journal American Water Works Association, 90(2), 60-70. 
Dalhuisen, J. M., Florax, R., de Groot, H. L. F., and Nijkamp, P. (2003). "Price and income elasticities of residential water demand: A meta-analysis." Land Economics, 79(2), 292-308.

Espey, M., Espey, J., and Shaw, W. D. (1997). "Price elasticity of residential demand for water: A metaanalysis." Water Resources Research, 33(6), 1369-1374.

Garcia-Alcubilla, R., and Lund, J. R. (2006). "Derived willingness-to-pay for household water use with price and probabilistic supply." Journal of Water Resources Planning and Management-Asce, 132(6), 424-433.

Gaudin, S. (2006). "Effect of price information on residential water demand." Applied Economics, 38(4), 383-393.

Hanemann, W. M. (1998). "Price and Rate Structures." Urban Water Demand Management and Planning, D. D. Baumann, J. J. Boland, and W. M. Hanemann, eds., McGraw-Hill, Inc., New York, 137-175.

Howe, C. W., and Linaweaver, F. (1967). "Impact of Price on Residential Water Demand and Its Relation to System Design and Price Structure." Water Resources Research, 3(1), 13-32.

Howe, C. W., Russell, C. S., Young, R. A., and Vaughan, W. J. (1971). "Future Water Demands: the impacts of technolgical change, public policies, and changing market conditions on the water patterns of selected sectors of the United States Economy: 1970-1990." NWC-EES-71-001, National Water Commission, Arlington, VA.

Kenney, D. S., Goemans, C., Klein, R., Lowrey, J., and Reidy, K. (2008). "Residential Water Demand Management: Lessons from Aurora, Colorado." Journal of the American Water Resources Association, 44(1), 192-207, DOI: 10.1111/j.1752-1688.2007.00147.x.

Nieswiadomy, M., and Cobb, S. L. (1993). "Impact of Pricing Structure Selectivity on Urban Water Demand." Contemporary Policy Issues, 11(3), 101-113. 
Nieswiadomy, M. L., and Molina, D. J. (1989). "Comparing Residential Water Demand Estimates under Decreasing and Increasing Block Rates Using Household Data." Land Economics, 65(3), 280-289.

Olmstead, S. M., Hanemann, W. M., and Stavins, R. N. (2007). "Water demand under alternative price structures." Journal of Environmental Economics and Management, 54(2), 181-198.

Rosenberg, D. E., Talozi, S., and Lund, J. R. (2008). "Intermittent Water Supplies: Challenges and Opportunities for Residential Water Users in Jordan." Water International, 33(4), 488-504.

Rosenberg, D. E., Tarawneh, T., Abdel-Khaleq, R., and Lund, J. R. (2007). "Modeling Integrated WaterUser Decisions in Intermittent Supply Systems." Water Resources Research, 43(7), W07425.10.1029/2006WR005340.

Salman, A., Al-Karablieh, E., and Haddadin, M. (2008). "Limits of pricing policy in curtailing household water consumption under scarcity conditions." Water Policy, 10(3), 295-304.

Stevens, T. H., Miller, J., and Willis, C. (1992). "Effect of Price Structure on Residential Water Demand." Water Resources Bulletin, 28(4), 681-685.

Theodory, G. (2000). "The willingness and ability of residential and non-residential subscribers in Greater Amman to pay more for water." PN-ACQ-616, Development Alternative, Inc., and U.S. Agency for International Development, Bethesda, Maryland, available at http://dec.usaid.gov/index.cfm?p=search.getCitation\&CFID $=4686300 \& C F T O K E N=50535563 \&$ rec no=116108.

Young, R. A. (2005). Determining the Economic Value of Water: Concepts and Methods, Resources for the Future, Washington, D.C.

404

405

406 
408 Figure 1. Generalized depiction of marginal price (left) and total charges (right) for various rate structures

409 Figure 2. Demand responses for different rate structures and price schedules using average (top) and marginal (bottom) prices

Figure 3. Tradeoffs between cost allocation among users, cost recovery, economic efficiency, and water use for different simulated rate structures and price schedules. Plots on the left show tradeoffs as a function of water use. Plots on the right show tradeoffs as a function of economic efficiency measured as users' total costs for piped water, alternative sources, and coping actions.

415 Figure 4. Cost allocations among users for different revenue neutral rate structures and price schedules

416 Figure 5. Tradeoffs for cost allocation (top), water use (second), economic efficiency (third), and cost recovery (bottom) between the flat charge and price components for the uniform rate structure 


\section{Table 1. Econometric studies reporting price elasticities of water demand for multiple rate structures}

\begin{tabular}{|c|c|c|c|c|c|c|c|c|c|c|}
\hline \multicolumn{4}{|c|}{ Data Set Characteristics } & \multicolumn{3}{|c|}{ Price Elasticities for Rate Structures } & \multicolumn{3}{|c|}{ Regression Attributes } & \multirow[b]{2}{*}{ Reference } \\
\hline Year & Location & $\begin{array}{l}\text { Sample } \\
\text { size }\end{array}$ & Type & Uniform & $\begin{array}{l}\text { Increasing } \\
\text { block }\end{array}$ & $\begin{array}{l}\text { Decreasing } \\
\text { block }\end{array}$ & $\begin{array}{c}\text { Price } \\
\text { variables }^{\mathrm{a}}\end{array}$ & Method $^{b}$ & $r^{2}$ & \\
\hline 1. 1988 & Mass., US & 85 & Aggregate, panel & -0.41 & -0.54 & -0.69 & $A P$ & $2 S L S$ & $0.18-0.55$ & Stevens et al (1992) \\
\hline 2. $1976-1985$ & Denton, TX & 101 & $\begin{array}{l}\text { Cross-sectional, } \\
\text { time-series }\end{array}$ & & -0.55 & -0.36 & $\mathrm{MP}, \mathrm{D}$ & 2SLS, IV & $0.16-0.26$ & $\begin{array}{l}\text { Nieswiadomy and } \\
\text { Molina (1989) }\end{array}$ \\
\hline 3. 1984 & US & 109 & Aggregate, panel & & -0.17 to -0.63 & -0.27 to -0.46 & $A P, M P, S P$ & Logit & $0.22-0.60$ & $\begin{array}{l}\text { Nieswiadomy and Cobb } \\
\text { (1993) }\end{array}$ \\
\hline 4. $1996-1998$ & 11 US Cities & 1082 & $\begin{array}{l}\text { Cross-sectional, } \\
\text { panel }\end{array}$ & -0.33 & -0.59 & & & DCC & & Olmstead et al (2007) \\
\hline 5. $2000-2005$ & Aurora, CA & 10,000 & $\begin{array}{l}\text { Cross-sectional, } \\
\text { time-series }\end{array}$ & -0.6 & -0.65 & & AP & FE-IV & 0.4 & Kenney et al (2008) \\
\hline
\end{tabular}

Notes:

a. $\mathrm{AP}=$ average price; $\mathrm{MP}=$ marginal price; $\mathrm{SP}=\mathrm{Sh}$ in price; $\mathrm{D}=$ difference

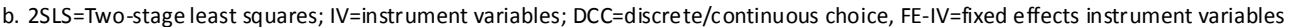


Table 2. Meta analysis of water demand studies reporting the influence of rate structures on price-elasticity of water demand

\begin{tabular}{lcc}
\hline Study Descriptor & Espy et al (1997) & Dalhuisen et al (2003) \\
\hline Years & $1967-1993$ & $1967-1998$ \\
Articles reviewed & 24 & 64 \\
Model estimates & 127 & 314 \\
Relative influence & & \\
$\quad$ Increasing blocks & $0.34-0.62$ & $0.35-0.54$ \\
Declining blocks & $0.18-0.38$ & $0.14-0.32$ \\
Regression methods & Semi-log; Box-Cox & Linear; Box-Cox \\
\multicolumn{1}{c}{$r^{2}$} & $0.41-0.81$ & 0.22 \\
\hline
\end{tabular}




\section{Table 3. Price schedules for different simulated rate structures}

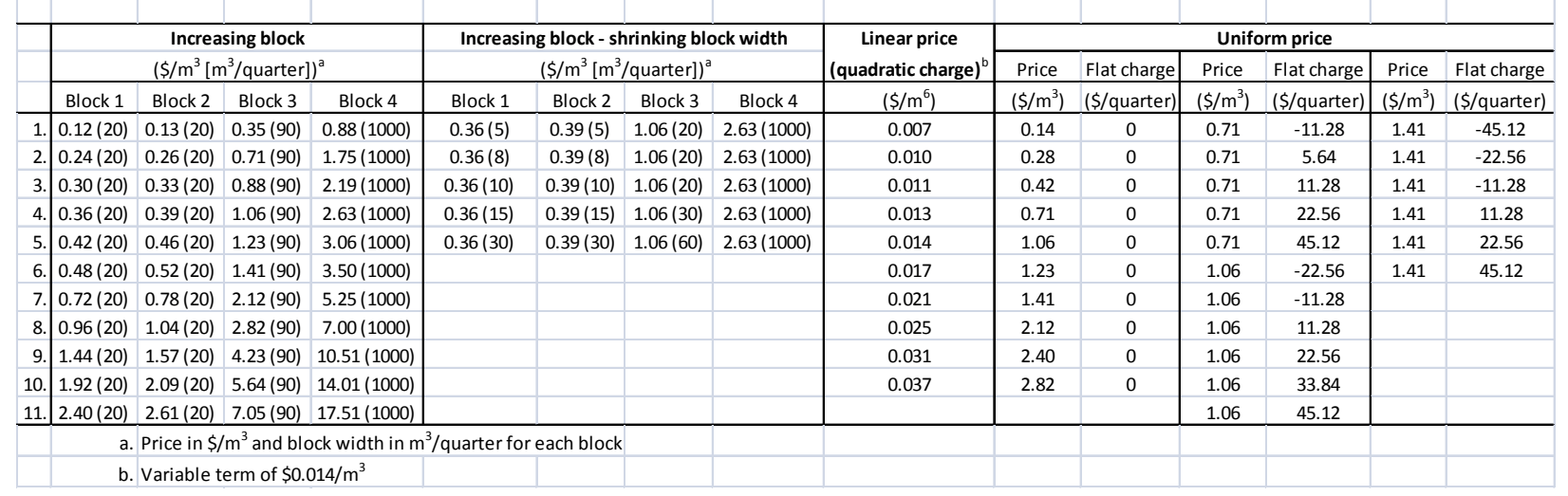


Table 4. Calculated price elasticities for different rate structures, prices, and price variables

\begin{tabular}{|c|c|c|c|c|}
\hline \multirow{2}{*}{ Rate Structure } & \multicolumn{2}{|c|}{ Historical Prices (inelastic range) } & \multicolumn{2}{|c|}{ Higher Prices (elastic range) } \\
\hline & Average price $^{a}$ & Marginal price ${ }^{\mathrm{b}}$ & Average price $^{a}$ & Marginal price ${ }^{b}$ \\
\hline Increasing block & 0.00 to -0.01 & 0.00 to -0.01 & -0.78 to -1.82 & -0.51 to -1.49 \\
\hline IBR-shrinking block width & & & -0.48 to -0.41 & \#DIV/0! \\
\hline Linear price (quadratic charge) & -0.08 to -0.11 & -0.06 to -0.10 & -0.92 to -1.06 & -0.60 to -0.72 \\
\hline Uniform (no flat charge) & 0.00 to -0.01 & 0.00 to -0.01 & -1.47 to -2.39 & -1.47 to -2.39 \\
\hline Uniform $\left(\$ 0.71 / \mathrm{m}^{3}\right.$ with flat charges) & -0.02 to -0.05 & \#DIV/0! & -0.32 to -0.58 & \#DIV/0! \\
\hline Uniform ( $\$ 1.06 / \mathrm{m}^{3}$ with flat charges) & -0.05 to -0.11 & \#DIV/0! & -0.81 to -0.98 & \#DIV/0! \\
\hline Uniform ( $\$ 1.41 / \mathrm{m}^{3}$ with flat charges) & -0.04 to -0.10 & \#DIV/0! & -1.53 to -2.98 & \#DIV/0! \\
\hline Historical & -0.02 to -0.03 & -0.16 to -0.16 & & \\
\hline \multicolumn{5}{|l|}{ Notes: } \\
\hline \multicolumn{5}{|c|}{ a. Average price $=($ Total revenues from piped water sales) $/$ (Total piped water use) } \\
\hline b. Marginal price $=$ Marginal price at $a$ & average piped wa & er use & & \\
\hline
\end{tabular}

